\title{
Phylogenetic assessment of Chaetomium indicum and allied species, with the introduction of three new species and epitypification of $C$. funicola and $C$. indicum
}

\author{
Xue-Wei Wang • Xiao-Liang Wang • Fu-Jiang Liu • \\ Xiao-Meng Zhao $\cdot$ Jing Li $\cdot$ Lei Cai
}

Received: 4 February 2013 /Revised: 8 December 2013 / Accepted: 11 December 2013 /Published online: 4 January 2014

(C) The Author(s) 2014. This article is published with open access at Springerlink.com

\begin{abstract}
Historically, the Chaetomium indicum group contained six species with similar ascus and ascospore morphology. Large morphological variation in their branched ascomatal hairs often resulted in ambiguous species delimitation. In this study, morphological characters and the maximum growth temperature (MGT) are evaluated in light of phylogenetic relationships. Multigene phylogenetic analyses with ribosomal internal transcribed spacer (ITS), partial ribosomal large subunits (28S rDNA), $\beta$-tubulin, the translation elongation factor $1 \alpha$ (TEF1- $\alpha)$, and the largest subunit of RNA polymerase II (RPB1) recognize eight well-supported lineages within the monophyletic $C$. indicum group. The eight lineages correspond to five known species and three new species described in this paper (i.e., C. pratense, C. subfunicola, and C. ramosissimum). Chaetomium dolichotrichum is resurrected, as it appears to be a distinct species from C. funicola. Chaetomium cancroideum, though phylogenetically consistent with $C$. funicola, is retained as separate because of its distinct morphology. Both C. funicola and C.indicum are epitypified to stabilize the taxonomy.
\end{abstract}

Keywords Chaetomiaceae · Phylogeny · Taxonomy

\section{Introduction}

The genus Chaetomium Kunze is characterized by ostiolate ascomata covered by characteristic hairs, fasciculate and often

X.-W. Wang $(\bowtie) \cdot$ X.-L. Wang $\cdot$ F.-J. Liu $\cdot$ X.-M. Zhao $\cdot$ J. Li $\cdot$ L. Cai

State Key Laboratory of Mycology, Institute of Microbiology, Chinese Academy of Sciences, No. 3, 1st Beichen West Road, Chaoyang District, Beijing 100101, China

e-mail: wangxw@im.ac.cn evanescent asci, and single-celled, smooth and pigmented ascospores with germ pores (von Arx et al. 1986). Chaetomium colonizes a variety of substrates, and contains many species with cellulolytic capacity (Lee and Hanlin 1999). A few species have been reported to cause human infection (Koch and Haneke 1965; Abbott et al. 1995; Barron et al. 2003).

More than 400 species have been described in Chaetomium according to the statistics of Index Fungorum. Historically, ascomatal hairs have been considered important in distinguishing Chaetomium species (Chivers 1915; Skolko and Groves 1948, 1953; Ames 1961; Mazzucchetti 1965; Seth 1970), which can be straight (seta-like), flexuous, arcuate, undulate, circinate, spirally coiled or variously branched. After examining the ornamentation of the hairs in detail, Hawksworth and Wells (1973) concluded that the types of hair ornamentation lacked taxonomic value. Other authors suggested that the morphology of the hairs varied with culture conditions and the age of ascomata (Tschudy 1937; von Arx et al. 1984). Millner (1977) inferred that the growth responses of Chaetomium to temperature were useful in identifying closely related species. Subsequently, researchers paid increasing attention to the morphology of asci, ascospores and the germ pores (Dreyfuss 1976; Millner et al. 1977; von Arx et al. 1984; Cannon 1986). In a monographic study, von Arx et al. (1986) treated a number of species as synonyms that had been proposed primarily on the basis of the differences in ascomatal hairs. Their treatments have been extensively followed (Gené and Guarro 1996; Udagawa et al. 1997; de Cock and Hennebert 1997; Rodríguez et al. 2002; Doveri 2013). At present, less than 160 species are accepted within Chaetomium (Kirk et al. 2008; Asgari and Zare 2011; Doveri 2013).

Members of the $C$. indicum group have dichotomously branched ascomatal hairs. The existence of numerous variant forms of the hairs have complicated the classification of 
C. indicum Corda and allied species. Based on the presence or absence of unbranched terminal hairs and the characters of the branched hairs, Skolko \& Grover (1948) circumscribed and accepted C. cancroideum Tschudy, C. dolichotrichum Ames, C. erectum Skolko \& Groves, C. funicola Cooke, C. indicum and C. reflexum Skolko \& Groves in the group. This treatment was followed by most subsequent mycologists (Ames 1961; Mazzucchetti 1965; Seth 1970). However, von Arx et al. (1986) definitely accepted only two species: $C$. indicum and C. funicola. Chaetomium indicum was described to show typical dichotomously branched ascomatal hairs, while $C$. funicola was described to produce two types of hairs: long, seta-like or occasionally apically branched hairs, and short, repeatedly dichotomously branched hairs. Based on this classification, von Arx et al. (1986) incorporated C. dolichotrichum into C. funicola. Meanwhile, the same authors tentatively kept three intermediates as the relatives of $C$. indicum, namely C. cancroideum with incurved branches of hairs, C. erectum with erect and only apically branched hairs, and $C$. reflexum with reflexed branches of hairs. All these taxa together with C. indicum and C. funicola have asci and ascospores with similar morphologies. Asexual states have not been found in this group.

Molecular phylogenetic studies of Chaetomium have been conducted by several authors (Lee and Hanlin 1999; Untereiner et al. 2001; Greif et al. 2009; Asgari and Zare 2011). However, because of the limited sampling in previous studies, the phylogenetic relationships among the majority of Chaetomium species remain unclear, and the current circumscriptions of these Chaetomium species lack phylogenetic evaluation.

The objectives of the present study were to recognize phylogenetic species within the $C$. indicum group, and to determine their evolutionary relationships. Based on a larger sampling, the phylogenetic position of this group in the whole genus is estimated by a three-gene phylogeny. The study also assessed the morphological characters in light of the phylogenetic relationships, and the potential use of maximum growth temperature (MGT) for species discrimination in the C. indicum group.

\section{Material and methods}

Cultures and morphology

Twenty-three strains representing six putative species were selected. The isolates studied are listed in Table 1. Eight strains were obtained from the CBS-KNAW Fungal Biodiversity Centre, Utrecht, Netherlands (CBS), including extype strains of $C$. erectum (CBS 140.56), C. dolichotrichum (CBS 162.48, preserved as C. funicola) and C. reflexum
(CBS 157.49), and other authentic strains of $C$. indicum (CBS 212.74 and CBS 860.68), C. funicola (CBS 159.52) and C. cancroideum (CBS 154.52 and CBS 136.38). Each of these strains has been used as a basis of description for each respective species by von Arx et al (1986). Other strains were isolated in China and preserved at the China General Microbiological Culture Collection Centre in the Institute of Microbiology (CGMCC), and five strains in CBS. Dried cultures of holotypes were preserved at the Herbarium Mycologicum Instituti Microbiologici Academiae Sinicae (HMAS).

All the strains were inoculated on cornmeal (3\%) agar (CMA), and incubated in the dark at $25^{\circ} \mathrm{C}$ until the ascomata matured. The features of the ascomata, ascomatal hairs, ascomal wall structures, asci, and ascospores were microscopically examined.

\section{Maximum growth temperature (MGT)}

The MGT for all strains studied was determined in two phases. The first phase provided a rough estimate of MGT (with $5{ }^{\circ} \mathrm{C}$ intervals), and the second provided a finer estimate (with $1{ }^{\circ} \mathrm{C}$ intervals). In the first phase, agar discs of 3-mm-diam were cut from the border of a 1-week-old colony of each strain grown at $25{ }^{\circ} \mathrm{C}$ on CMA. Each inoculum disc was inverted onto a 90-mm-diam Petri dish containing potato dextrose agar (PDA). The dishes were kept at $25,30,35,40$, and $50^{\circ} \mathrm{C}$, with three replicate dishes for each combination of strain and temperature. After 4 days, the colony diameters were measured, and the MGT that supported growth was determined. In the second phase, the inoculated dishes were kept at the maximum temperature that supported growth in the first phase, and five higher temperatures with $1{ }^{\circ} \mathrm{C}$ intervals, respectively, i.e., if the maximum temperature supporting growth was $30{ }^{\circ} \mathrm{C}$ in the first phase, dishes were kept at $30,31,32,33$, and $34{ }^{\circ} \mathrm{C}$ in the second phase of the experiment. Based on the results of the second phase, the MGT of each strain was determined (Table 1).

DNA extraction, PCR amplification, sequence alignment and phylogenetic analyses

Total genomic DNA was extracted from cultures using the E.Z.N.A. ${ }^{\text {TM }}$ HP Fungal DNA Kit (Omega) following the manufacturer's instruction with minor modifications. PCRamplifications were conducted in a Thermo Hybaid Px2 Thermal Cycler (Thermo Hybaid Co., US) using the following primer sets: ITS4/ITS5 for the complete ITS1/5.8S/ITS2 regions (White et al. 1990), NL1/NL4 for D1/D2 domains of 28S rDNA (O’Donnell 1993), T1 (O’Donnell and Cigelnik 1997)/T222 (Bt2b) (Glass and Donaldson 1995) for partial $\beta$ tubulin (BTUB) gene, EF983/EF2218R (AFTOL, http://aftol. 


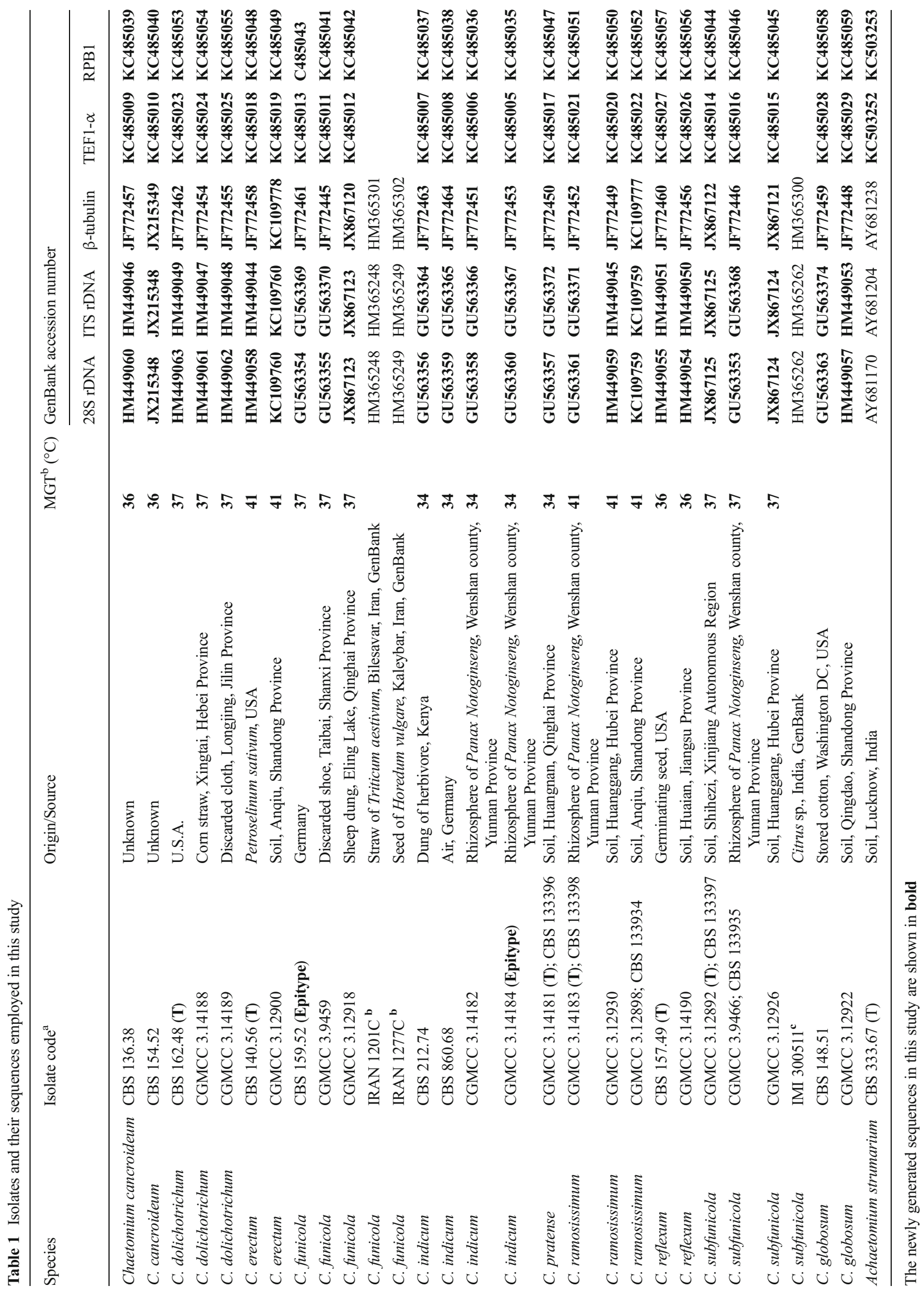


org/) for partial translation elongation factor $1 \alpha$ (TEF1- $\alpha$ ) gene, and RPB1-Af/RPB1-Cr (Matheny et al. 2002) for partial fragments of the largest subunit of RNA polymerase II (RPB1) genes, respectively. The PCR reaction $(50 \mu \mathrm{L})$ contained $0.25 \mu \mathrm{M}$ of each primer, $0.5 \mathrm{mM} \mathrm{dNTP}, 0.8 \mathrm{U}$ of Taq DNA polymerase in $1 \times$ reaction buffer containing $2 \mathrm{mM}$ $\mathrm{MgCl} 2$ with $2 \mu \mathrm{L}$ of template. The PCR programs consisted of an initial denaturation of $5 \mathrm{~min}$ at $95{ }^{\circ} \mathrm{C}$ followed by 30 cycles of denaturation at $94{ }^{\circ} \mathrm{C}$ for $1 \mathrm{~min}$, annealing at $49{ }^{\circ} \mathrm{C}$ (for ITS and RPB1) or $55^{\circ} \mathrm{C}$ (for $28 \mathrm{~S}$ rDNA D1/D2 domain, BTUB and TEF1- $\alpha$ ) for $1 \mathrm{~min}$ and elongation at $72{ }^{\circ} \mathrm{C}$ for $2 \mathrm{~min}$, and a final extension of $72{ }^{\circ} \mathrm{C}$ for $10 \mathrm{~min}$. The purified PCR products were sequenced on an Applied Biosystems 3730Xl DNA Analyzer by SinoGenoMax Co. Ltd. (http://www.sinogenomax.com). The obtained sequences were deposited in GenBank (http://www.ncbi. nlm.nih.gov, Table 1).

Sequences of each gene partition were initially aligned using Clustal X 1.83 (Thompson et al. 1997), and were manually edited to optimize homology using BioEdit 5.0.9 (Hall 1999). All five gene regions were then concatenated into a combined dataset consisting of 23 target taxa, two C. globosum strains and one Achaetomium strain (Tree-Base ID: 13834). For ITS, 28S rDNA and BTUB gene regions, and 33 published sequences were available (Asgari and Zare 2011) to allow an expanded dataset (56 taxa, Tree-Base ID: 13833) for determining the phylogenetic positions of the members of this group in the whole Chaetomium genus. The datasets in NEXUS and PHYLIP formats from both five-gene and three-gene datasets were used for the phylogenetic analysis.

Bayesian phylogenetic analysis, maximum likelihood analysis and maximum parsimony were conducted. The best-fit model of evolution was determined by jModelTest 0.1.1 (Posada 2008). Bayesian analysis was performed with MrBayes 3.1.2 (Ronquist and Huelsenbeck 2003). Four MCMC chains were run simultaneously for $6 \times 10^{5}$ or $2 \times$ $10^{6}$ generations for the two datasets. Trees were sampled from every $300^{\text {th }}$ or $1000^{\text {th }}$ generation. After the first $25 \%$ of the trees were discarded, posterior probabilities were determined from a consensus tree generated from the remaining trees. Maximum likelihood analysis was performed using RAxML-VI-HPC 7.0.3 (Stamatakis 2006) with nonparametric bootstrapping using 1,000 replicates. In the maximum parsimony, all characters were equally weighted and unordered, and gaps were treated as missing data. Phylogenetic trees were inferred in PAUP 4.0b8 (Swofford 2001) by Maximum Parsimony (MP) using a heuristic search with 1,000 random sequence additions, tree bisectionreconnection (TBR) branch swapping, and MulTrees ON. The robustness of the trees was evaluated with 1,000 bootstrap replications. Trees were viewed in FigTree v1.1.2 (Rambaut 2009).

\section{Results}

Morphology

All strains examined in this study shared the following morphological characters: (1) ascospores typically shorter than $7.5 \mu \mathrm{m}$, ovate to broadly ovate or limoniform, bilaterally flattened and to appear ellipsoid, with an apical germ pore at the more attenuated end; (2) asci clavate, broadly clavate or obovate; (3) more or less dichotomously branched ascomatal hairs arising around the ostioles of spherical or ovate ascomata. Ascomatal wall is either textura intricata or angularis in surface view (Fig. 1).

\section{MGT}

Our results showed that all the tested strains within each species exhibit consistent MGTs (Table 1). The data of MGTs clearly split the $C$. indicum group into three value types (Table 2), with MGTs of $34{ }^{\circ} \mathrm{C}$ represented by $C$. indicum and $C$. pratense, $36-37^{\circ} \mathrm{C}$ by $C$. funicola, C. cancroideum, C. subfunicola, C. dolichotrichum and C. reflexum, and $41{ }^{\circ} \mathrm{C}$ by $C$. erectum and C. ramosissimum.

\section{Phylogeny}

The three-gene alignment (ITS, 28S rDNA, BTUB) comprised 56 taxa and 1,972 characters, of which 406 were parsimony-informative. The alignment of five genes (ITS, 28S rDNA, BTUB, TEF1- $\alpha$, RPB1) comprised 26 taxa and 3,630 characters, of which 800 were parsimony-informative. The best-fit models of evolution were estimated as the GTRGAMMA model for the three-gene dataset and the TIM1+ GAMMA model for the five-gene dataset. Bayesian analysis was conducted with the number of rate categories set to six, rates set to gamma, and all the remaining parameters followed the default. Maximum likelihood (ML) analysis was conducted under the GTR-GAMMA model of evolution (Stamatakis 2006). For the three-gene dataset, MP analysis generated nine equally most parsimonious trees with one of the trees described with $\mathrm{TL}=869, \mathrm{CI}=0.7883, \mathrm{RI}=0.9045, \mathrm{RC}=0.7130$ and $\mathrm{HI}=0.2117$. For the five-gene dataset, MP analysis generated four equally most parsimonious trees, with one of the trees described with $\mathrm{TL}=1696, \mathrm{CI}=0.7471, \mathrm{RI}=0.8853, \mathrm{RC}=$ 0.6613 and $\mathrm{HI}=0.2837$. The MP and ML analyses resulted in essentially concordant trees to that of Bayesian analysis. The Bayesian trees are presented (Figs. 5 and 6) with the respective MP and ML bootstrap proportions indicated.

Analyses based on both datasets recognized the monophyly of the $C$. indicum group that comprised eight wellsupported clades (Figs. 4 and 5). Chaetomium pratense, C. ramosissimum and C. subfunicola were introduced as new species based on distinct phylogenetic relationships and 
Fig. 1 Drawings of the wall structure of ascomata in surface view associated with this study. a textura intricata. b textura angularis

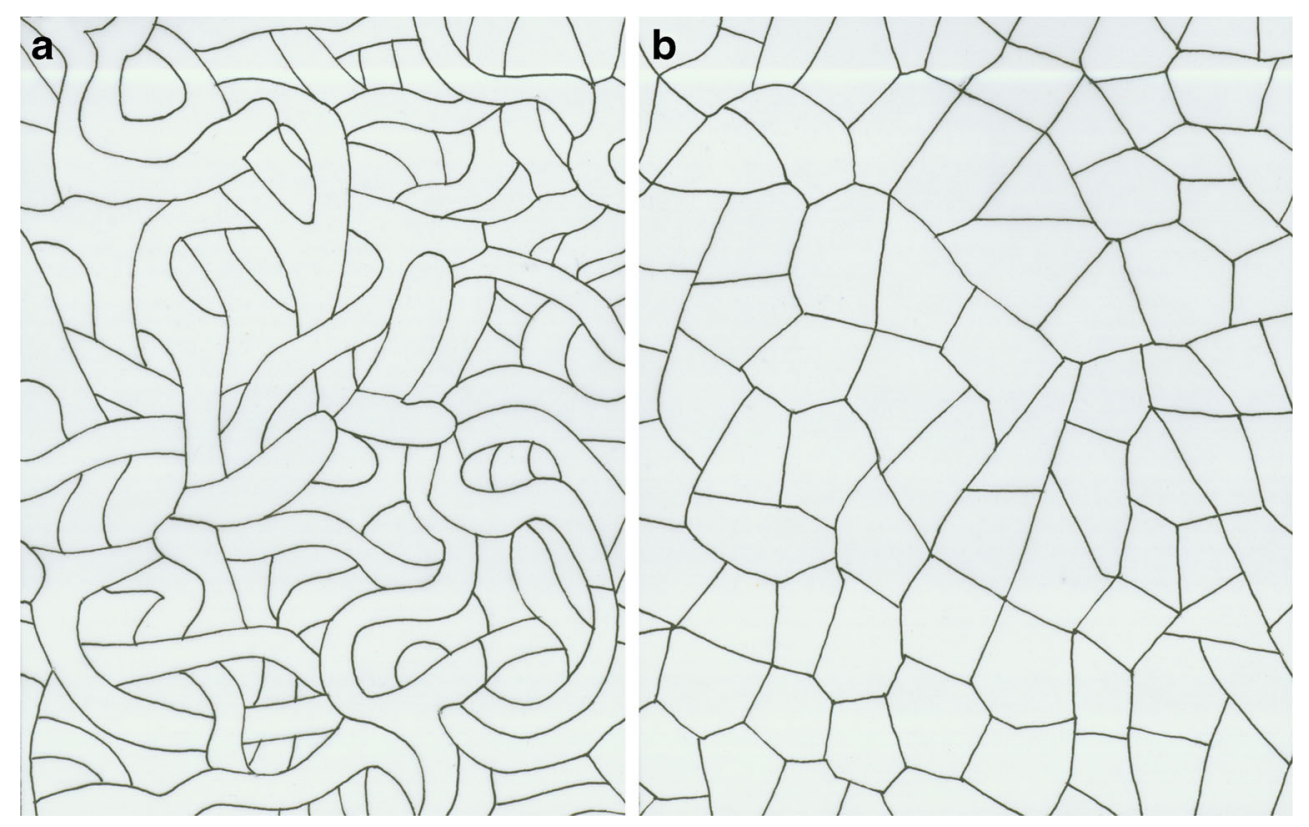

morphology. However, Chaetomium cancroideum, though it exhibits distinct morphology, appears non-separable from C. funicola.

\section{Taxonomy}

Chaetomium pratense X.W. Wang \& L. Cai, sp. nov., Fig. 2a-d.

\section{MycoBank MB 563348}

Etymology: Referring to its habitat in the pasture.

Colonies yellow, aerial hyphae sparse or absent, with yellow or orange exudate. Anamorph absent. Ascomata superficial, spherical or ovate, 160-250 $\mu \mathrm{m}$ high, 110-200 $\mu \mathrm{m}$ diam., ostiolate. Ascomatal wall composed of brown, irregular or elongate cells (textura intricata or epidermoidea). Terminal hairs erect, dichotomously branched 3-5(7) times at wide (nearly straight) angles and starting primarily from the upper half part, punctulate or verrucose. Lateral hairs unbranched, seta-like, tapering towards tips. Asci fasciculate, clavate, stalked, without apical structures, $26-48 \times 8-13 \mu \mathrm{m}, 8-$ spored, evanescent. Ascospores brown, broadly ovate, bilaterally flattened, ellipsoid, 5-7.5 $\times 4.5-6 \times 3-4 \mu \mathrm{m}$, with an apical germ pore at the more attenuated end.

Cardinal temperatures for growth: Minimum about $10{ }^{\circ} \mathrm{C}$, maximum $34{ }^{\circ} \mathrm{C}$, optimum $25^{\circ} \mathrm{C}$.

Holotype: China, Qinghai, Huangnan, from grassland soil, 8 June 2002, X.-W. Wang, HMAS 242921 (Holotype); culture ex-type CGMCC 3.14181.

Note: Phylogenetically, Chaetomium pratense is relatively close to $C$. indicum, $C$. funicola, and C. subfunicola. In morphology, $C$. pratense differs from $C$. indicum in producing larger and broadly ovate ascospores and the terminal hairs that start to branch from the upper half part; from C. subfunicola in having clavate asci and hairs not significantly different in length; from $C$. funicola in possessing broader ascospores and hairs not significantly different in length.

Chaetomium subfunicola X.W. Wang \& L. Cai, sp. nov., Fig. 3a-h.

\section{MycoBank MB 801733}

Etymology: Referring to its phenotypic similarity to the species C. funicola.

Colonies white or yellowish, aerial hyphae white, with yellow to green exudate. Anamorph absent. Ascomata superficial, nearly spherical or ellipsoid, 150-250 $\mu \mathrm{m}$ high, 170$235 \mu \mathrm{m}$ diam., ostiolate, with a brown wall of textura intricata or epidermoidea. Terminal hairs of two types verrucose: (1) longer, erectly extending above the cirrhus, dichotomously branched 2-8 times at the apices or seta-like, usually at acute angles and tapering towards a point; (2) shorter and dichotomously branched repeatedly, often obscured by cirrhi. Asci fasciculate, obovate or broadly clavate, 22-35 $\mu \mathrm{m}$ long, 10 $14 \mu \mathrm{m}$ diam. in spore-producing part, stalked, without apical structures, 8-spored, evanescent. Ascospores brown, ovate to broadly ovate, bilaterally flattened as ellipsoid, 5.5-7.5(10) $\times$ 4.5-5 (6) $\times 3-4 \mu \mathrm{m}$, with an apical germ pore at the more attenuated end.

Cardinal temperatures for growth: Minimum about $7{ }^{\circ} \mathrm{C}$, maximum $37^{\circ} \mathrm{C}$, optimum $28^{\circ} \mathrm{C}$.

Holotype: China, Xinjiang, Shihezi University, from garden soil, 3 Aug. 2007, F.-J. Liu, HMAS 244194 (Holotype), culture ex-type CGMCC 3.12892. 


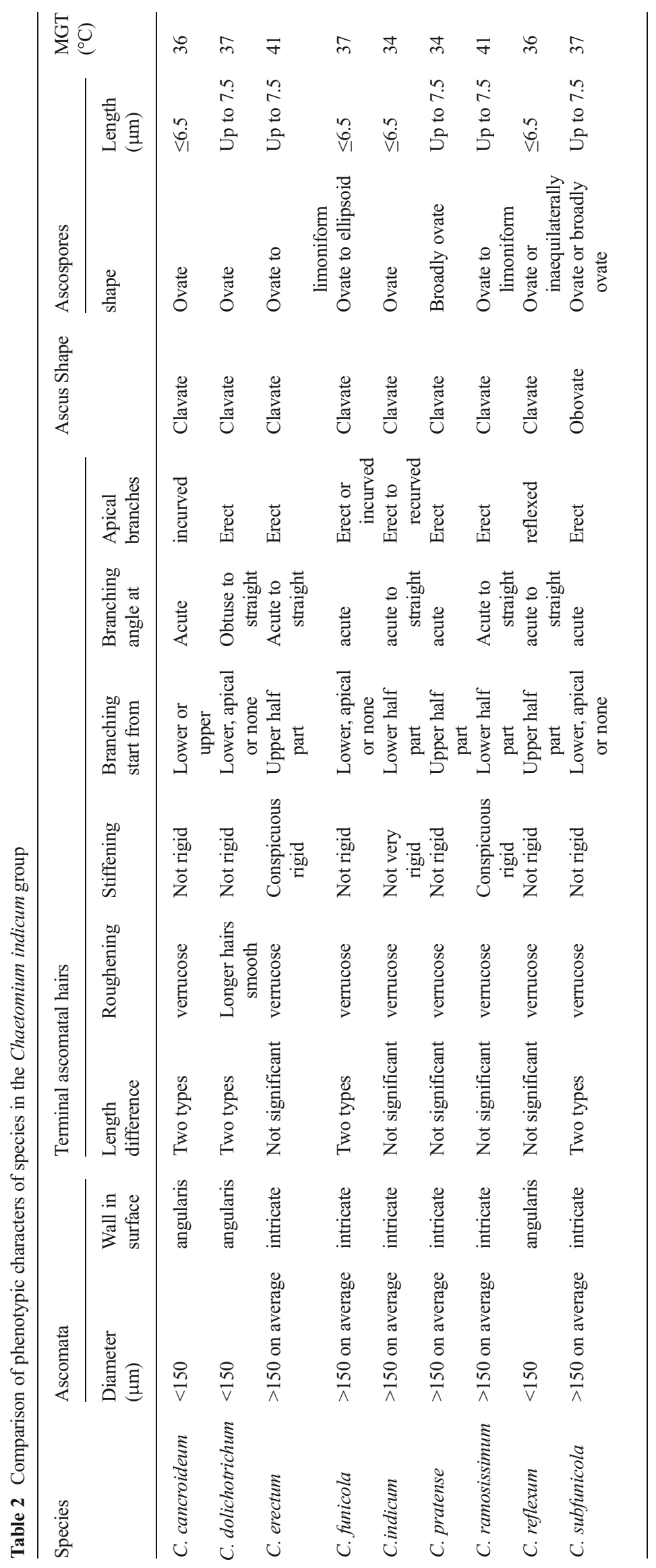




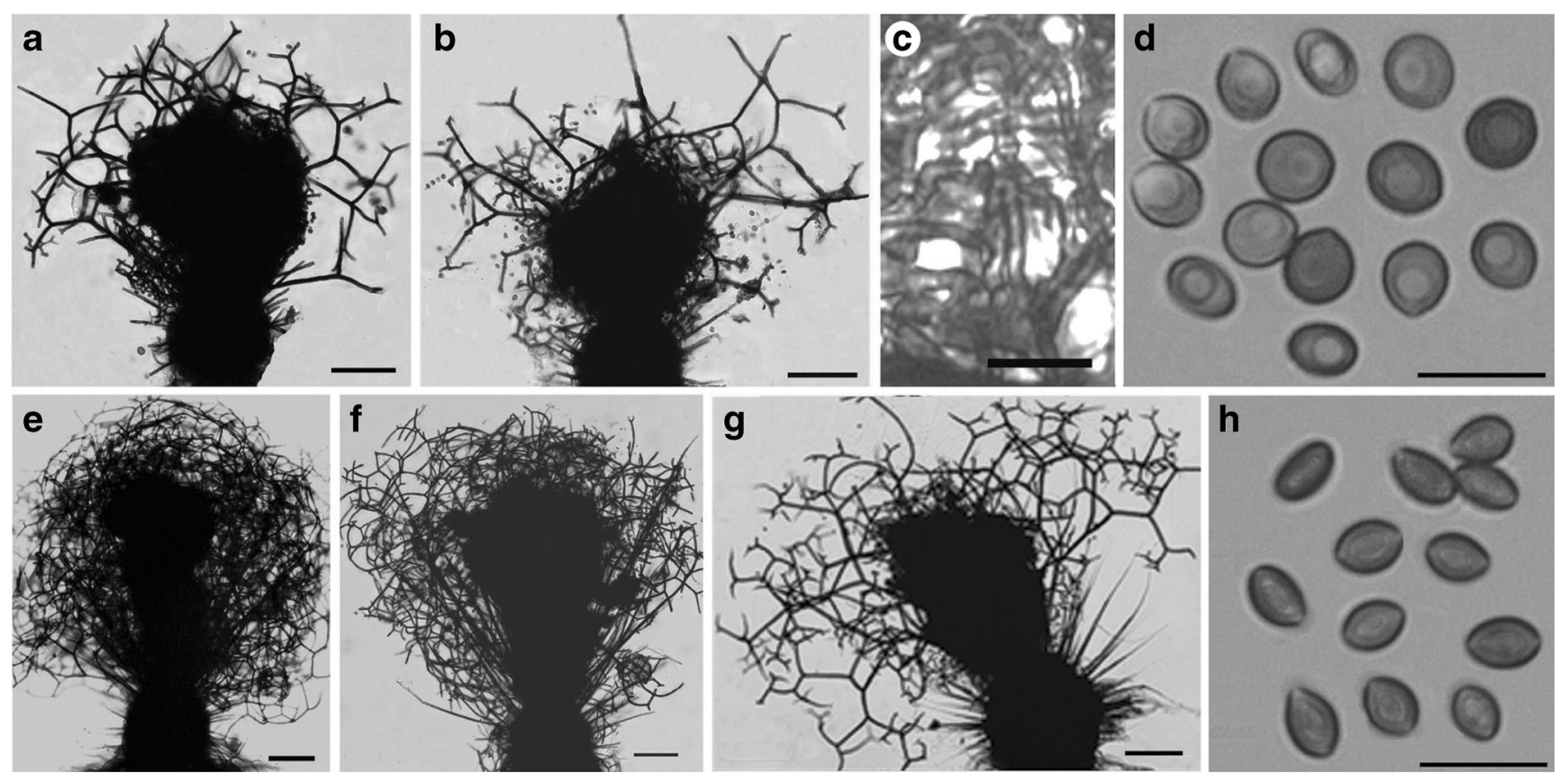

Fig. 2 a-d Chaetomium pratense (ex-type strain CGMCC 3.14181). a-b Ascoma. c Surface cellular texture of the ascomatal wall. d Ascospores. eh Chaetomium indicum. e-g Ascomata (e-f ex-epitype strain CGMCC
3.14184, g CBS 860.68). h Ascospores (ex-epitype strain CGMCC 3.14184). Bars: a, b, e, f, $\mathbf{g}=100 \mu \mathrm{m} ; \mathbf{c}, \mathbf{d}, \mathbf{h}=10 \mu \mathrm{m}$
Other strains examined: China, Yunnan, Wenshan county, from the rhizosphere of Panax Notoginseng, 11 Apr. 2003, X.Z. Liu, culture CGMCC 3.9466; China, Hubei, Huanggang city, from the soil, 8 Nov. 2008, F.-J. Liu, culture CGMCC 3.12926 .

Note: Chaetomium subfunicola is closely related to C. funicola, and distinguished by possessing obovate rather than clavate asci and broader or larger ascospores. The strain IMI 300511 was originally recognized as C. funicola by Asgari and Zare (2011). Though no morphological data of IMI 300511 are available, the strain is assigned here to C. subfunicola based on molecular evidence.

Chaetomium ramosissimum X. W. Wang \& L. Cai, sp. nov., Fig. 4a-d.

\section{MycoBank MB 801734}

Etymology: Referring to its terminal hairs more copiously branched than those of $C$. erectum.

Colonies yellow, aerial hyphae yellow, without exudate. Anamorph absent. Ascomata superficial, nearly spherical or ovate, $125-180 \mu \mathrm{m}$ high, $110-170 \mu \mathrm{m}$ diam., ostiolate, with a brown wall of textura intricata or epidermoidea. Terminal hairs erect, rigid, dark, copiously dichotomously branched more than four times at wide (nearly straight) angles and starting from the lower half part, punctulate or verrucose. Lateral hairs unbranched, seta-like, tapering. Asci fasciculate, clavate, stalked, without apical structures, $28-35 \times 8-12 \mu \mathrm{m}$, 8 -spored, evanescent. Ascospores brown, ovate to limoniform, bilaterally flattened as ellipsoid, 5-7.5 $\times 4.5-5.5$ $\times 3-4 \mu \mathrm{m}$, with an apical germ pore at the more attenuated end.

Cardinal temperatures for growth: Minimum about $10^{\circ} \mathrm{C}$, maximum $41{ }^{\circ} \mathrm{C}$, optimum $30^{\circ} \mathrm{C}$.

Holotype: China, Yunnan, Wenshan county, from the rhizosphere of Panax Notoginseng, 11 April, 2003, X.-Z. Liu, HMAS 244195 (Holotype), culture ex-type CGMCC 3.14183 .

Other strains examined: China, Hubei, Huanggan city, from the soil, 8 Nov. 2008, F.-J. Liu, culture CGMCC 3.12930; China, Shandong, Anqiu town, from the soil, 13 Aug. 2007, F.-J. Liu, culture CGMCC 3.12898.

Note: Chaetomium ramosissimum is closely related to $C$. erectum, but distinguished by the terminal hairs that branched copiously from the lower half part. Chaetomium ramosissimum also differs from the other species in the group by possessing limoniform ascospores and higher MGT.

Chaetomium dolichotrichum Ames, Mycologia 37: 145. 1945, Fig. 4i-1.

Specimen examined: USA, Tennessee, Great Smoky Mts., Cades Cove, 1945, L. M. Ames, culture ex-type CBS 162.48; CHINA, Hebei, Xingtai city, from corn straw, 16 Apr. 2009, $J$. Li, culture CGMCC 3.14188; CHINA, Jilin, Longjing county, from discarded cloth, 2 Nov. 2009, J. Li, culture CGMCC 3.14189.

Note: Chaetomium dolichotrichum produces ascomata with hairs differing markedly in length. Its longer hairs are usually two or more times as long as the shorter ones with no 


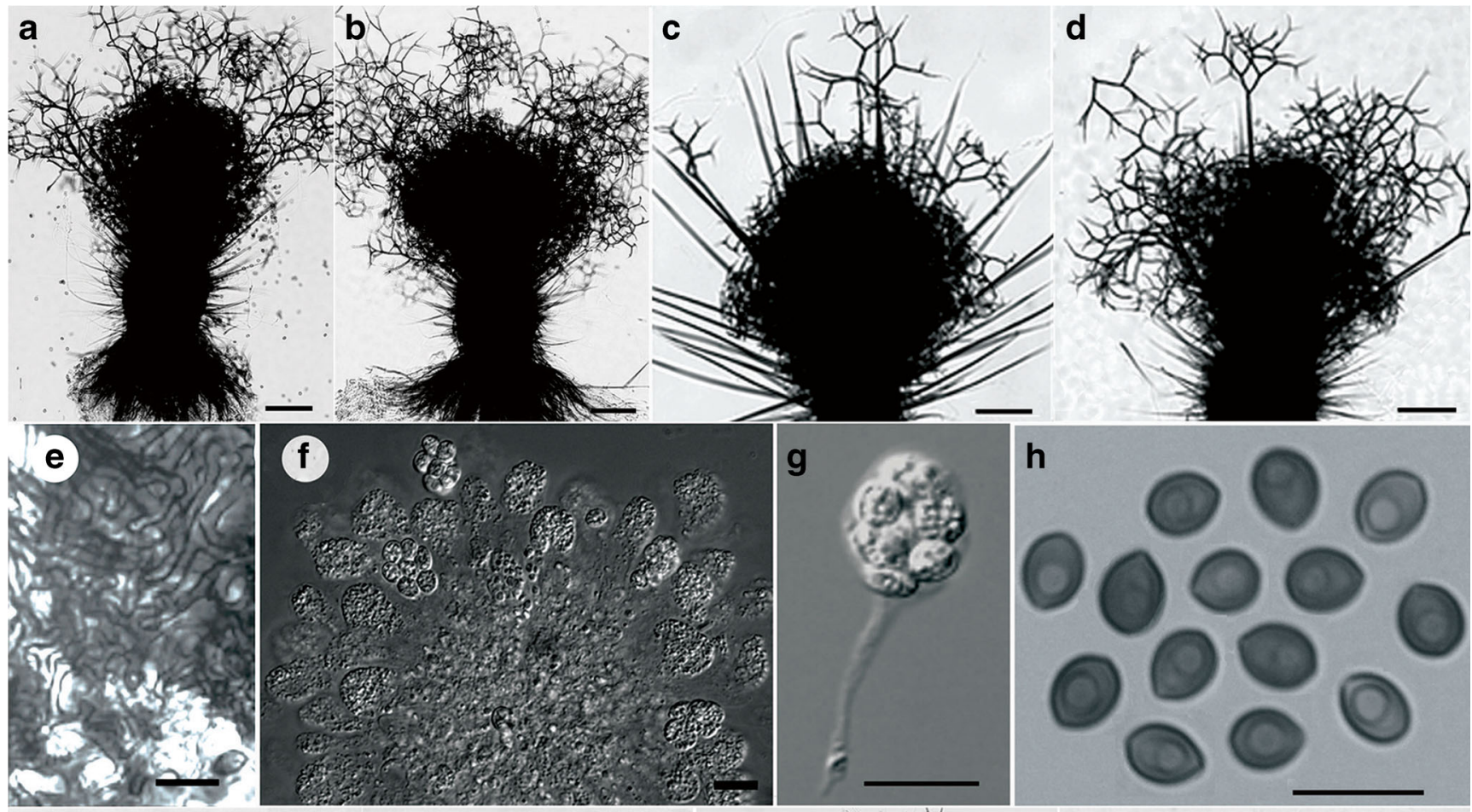

i

20 j
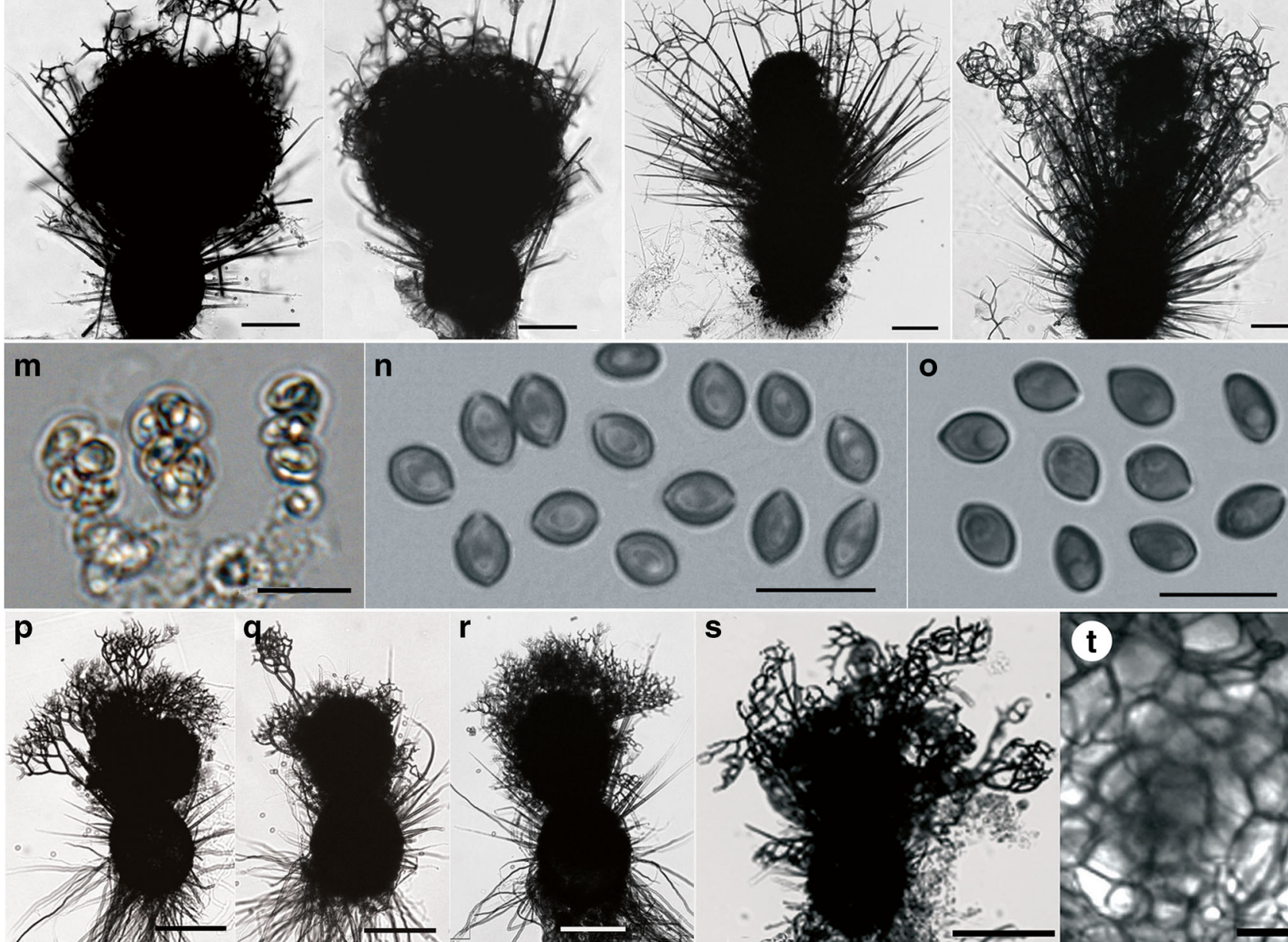

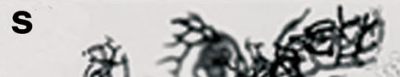

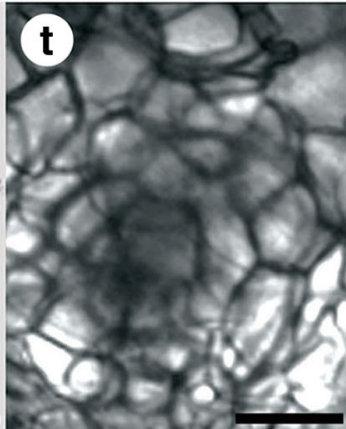


4 Fig. 3 a-h Chaetomium subfunicola. a-d Ascomata. (a-b ex-type strain CGMCC 3.12892, c-d CGMCC 3.9466). e Surface cellular texture of the ascomatal wall. $\mathbf{f} \mathbf{g}$ Asci. $\mathbf{h}$ Ascospores. $\mathbf{i} \mathbf{- o}$ Chaetomium funicola. $\mathbf{i}-\mathbf{I}$ Ascomata (i-j ex-epitype strain CBS 159.52, k CGMCC 3.12918. I CGMCC 3.9459). m Asci. n-o Ascospores (n ex-epitype strain CBS 159.52, o CGMCC 3.12918). p-t Chaetomium cancroideum (CBS 136.38). p-s Ascoma. t Surface cellular textures of the ascomatal wall. Bars: a-d, $\mathbf{i}-\mathbf{l}, \mathbf{p}-\mathbf{s}=100 \mu \mathrm{m} ; \mathbf{e}-\mathbf{h}, \mathbf{m}-\mathbf{0}, \mathbf{t}=10 \mu \mathrm{m}$ branches, and are tapering towards a point, or occasionally branched simply with long, terminal branches tapering towards a point (Figs. 4i-1, 5 and 6). Moreover, the longer hairs of $C$. dolichotrichum are smooth, which is quite unique in the C. indicum group, as all the other species produce verrucose hairs. Besides, C. dolichotrichum also produces smaller ascomata with the wall of textura angularis in contrast with C. funicola. The multigene phylogenies presented in this study
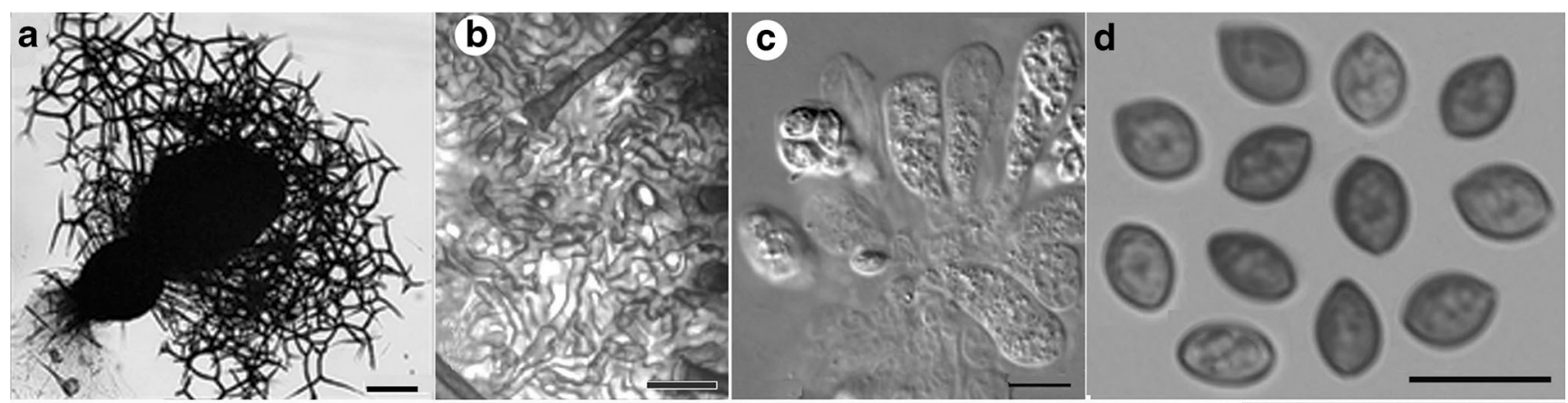

e
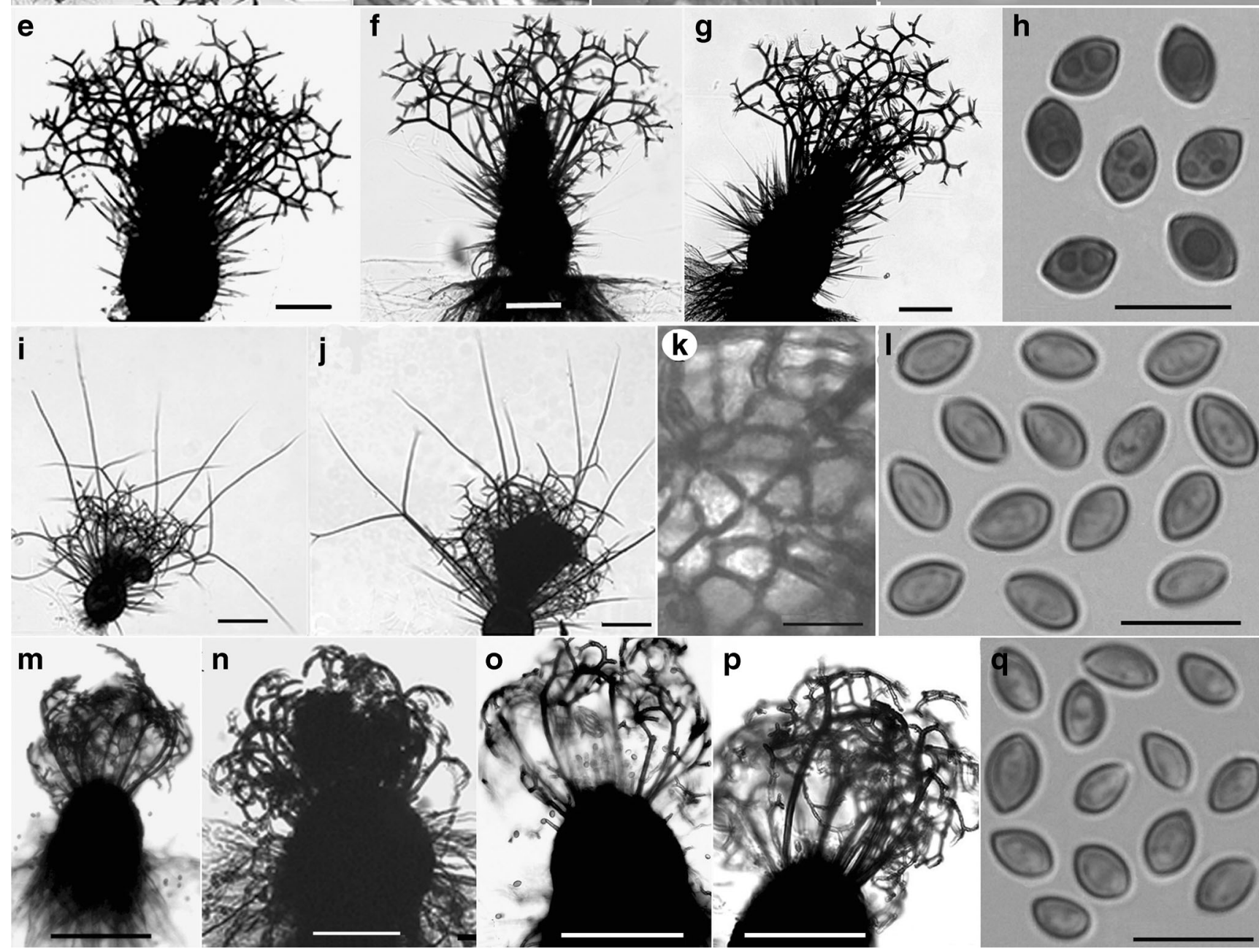

$p$
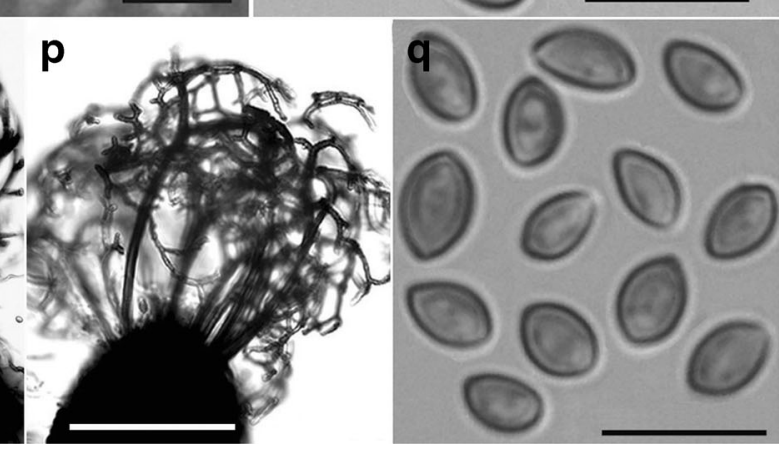

Fig. 4 a-d Chaetomium ramosissimum (ex-type strain CGMCC 3.14183). a Ascoma. b Surface cellular texture of the ascomatal wall. c Asci. d Ascospores. e-h Chaetomium erectum (ex-type strain CBS 140.56). e-g Ascoma. h Ascospores. i-l Chaetomium dolichotrichum

(ex-type strain CBS 162.48). $\mathbf{i}-\mathbf{j}$ Ascomata. $\mathbf{k}$ Surface cellular texture of the ascomatal wall. I Ascospores. m-q Chaetomium reflexum (ex-type strain CBS 157.49). m-p Ascoma. q Ascospores. Bars: $\mathbf{a}, \mathbf{e}-\mathbf{g}, \mathbf{i}-\mathbf{j}, \mathbf{m}-\mathbf{p}=$ $100 \mu \mathrm{m} ; \mathbf{b}-\mathbf{d}, \mathbf{h}, \mathbf{k}-\mathbf{l}, \mathbf{q}=10 \mu \mathrm{m}$ 


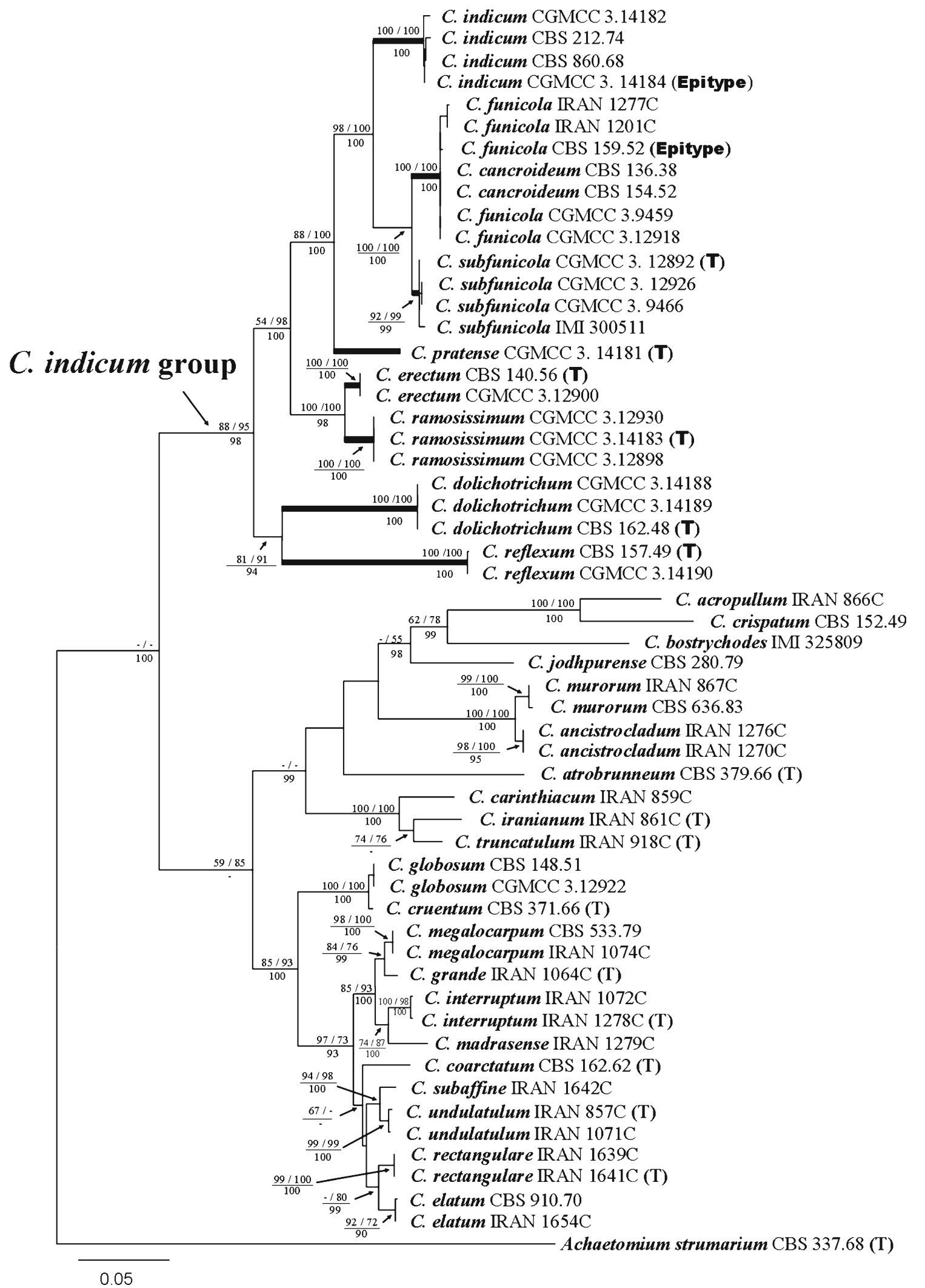

Fig. 5 Phylogram of Bayesian analysis based on the concatenation of ITS rDNA, 28S rDNA D1/D2 domain and the BTUB partition, with the confidence values of bootstrap proportions from MP analyses (before the backslash) and ML analyses (after the backslash) above branches, and the posterior probabilities from Bayesian analyses below branches. "-"means lacking statistic support ( $<50$ for bootstrap proportions from ML or MP analyses; $<90$ for posterior probabilities from Bayesian analyses). The C. indicum group comprising eight well-supported species (indicated using thickened branches) is revealed as a monophyletic clade in the genus 


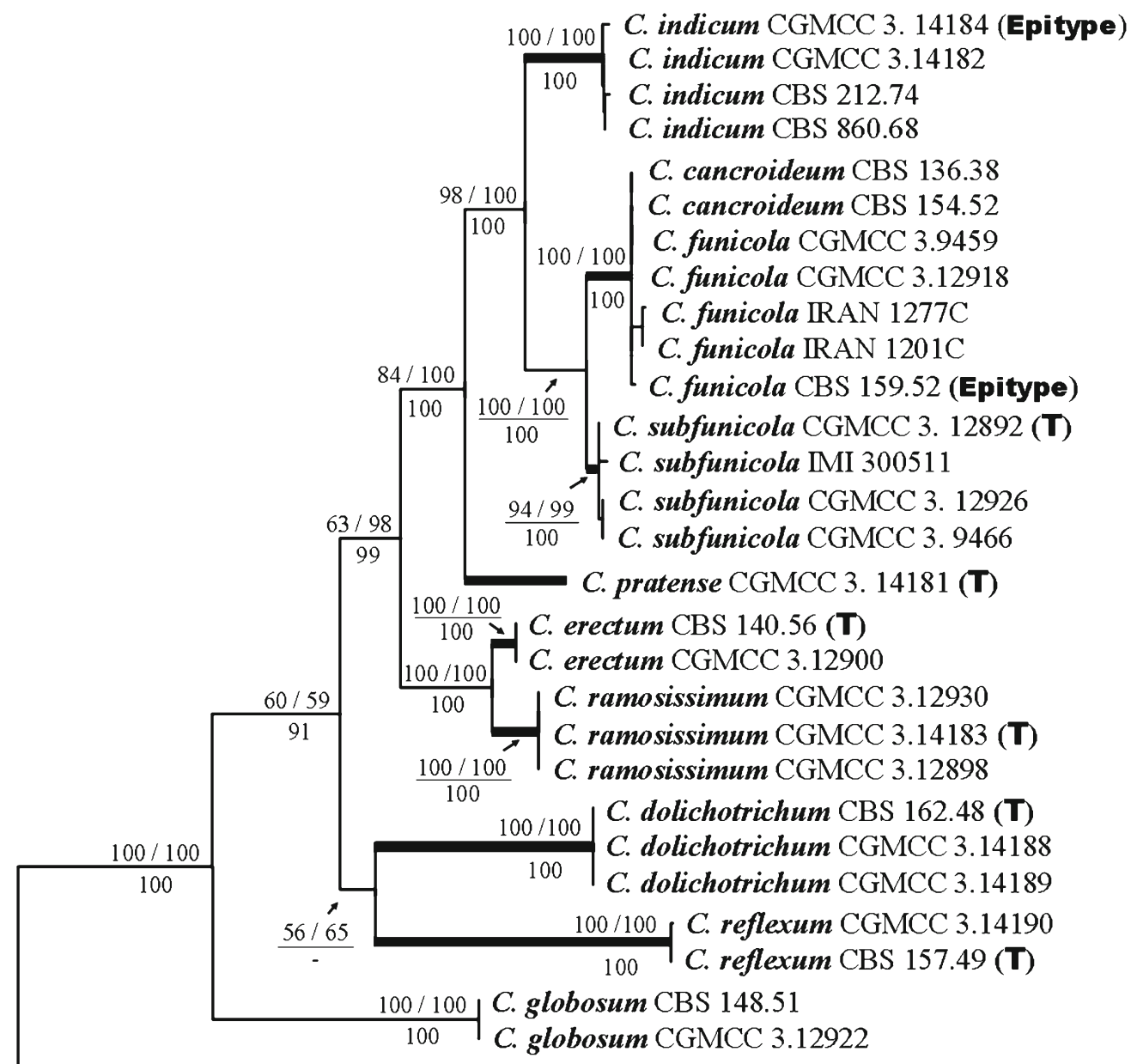

Achaetomium strumarium CBS 333.67 (T)

0.04

Fig. 6 Phylogram of Bayesian analysis based on the concatenation of five loci (ITS rDNA, 28S rDNA D1/D2 domain, BTUB, EF1- $\alpha$ and RPB1 gene partitions) with the confidence values of bootstrap proportions from MP analyses (before the backslash) and ML analyses (after the

revealed $C$. dolichotrichum to be a distinct species from C. funicola and other species in the group. Consequently, the synonymy of $C$. dolichotrichum with $C$. funicola (von Arx et al. 1986) is rejected.

Chaetomium funicola Cooke, Grevillea 1: 176. 1873, Fig. 3i-0.

Description of the epitype: Colonies white, aerial hyphae white to yellowish, with yellow exudate. Anamorph absent. Ascomata superficial, nearly spherical to ellipsoid, 150 $260 \mu \mathrm{m}$ high, 150-220 $\mu \mathrm{m}$ diam., ostiolate, with a brown wall of textura intricata or epidermoidea. Terminal hairs typically showing two types: (1) longer, erectly extending above the cirrhus, dichotomously branched 2-5 times at the apices, with branches straight or incurved, or unbranched (seta-like); (2) shorter and dichotomously branched repeatedly, often obscured by cirrhi. Asci fasciculate, clavate to broadly backslash) above branches, and the posterior probabilities from Bayesian analyses below branches. "-"means lacking statistic support $(<50$ for bootstrap proportions from ML or MP analyses; $<90$ for posterior probabilities from Bayesian analyses)

clavate, 24-36 $\mu \mathrm{m}$ long, $8-12 \mu \mathrm{m}$ diam. in spore-producing part, stalked, without apical structures, 8-spored, evanescent. Ascospores brown, ovate to broadly fusiform, bilaterally flattened as ellipsoid, 5-6.5 × 3.5-5 × 3-4 $\mu \mathrm{m}$, with an apical germ pore at the more attenuated end.

Cardinal temperatures for growth: Minimum about $9{ }^{\circ} \mathrm{C}$, maximum $37^{\circ} \mathrm{C}$, optimum $28^{\circ} \mathrm{C}$.

Specimens examined: Britain, British Museum, from twine, collection date unknown, M. C. Cooke, KEW(M) 189267, holotype, and an associated slide No. 144890 (Herbarium IMI, ex type collection). Germany, Bamberg, substrate unknown, R. Pfleger, deposited in CBS collection Sep. 1952, HMAS 244231 epitype designated here of $C$. funicola, culture ex-epitype CBS 159.52 (MBT 176686). China, Shanxi Province, Taibai, from discarded shoe, 12 June 2002, X.W. Wang, culture CGMCC 3.9459. China, Qinghai Province, 
Eling Lake, from sheep dung, 2 Aug. 2007, F.-J. Liu, culture CGMCC 3.12918.

Note: From the holotype of $C$. funicola, only ascospores and some ascomatal hairs on fragments of ascomata were observed that are morphologically similar to that of the epitype. The epitype is geographically close to that of the type locality.

Chaetomium cancroideum, represented by two authentic strains, CBS 136.38 (deposited in 1938 by Tschudy, who described this species) and CBS 154.52 (deposited by Ames in 1952), was found phylogenetically non-separable from C. funicola. Some morphological characters of C. cancroideum have also been uncovered that suggest its affinity to C. funicola. For example, parts of its ascomatal hairs are significantly longer than others (two types of ascomatal hairs). The incurved branches of ascomatal hairs, which had traditionally been used to distinguish $C$. cancroideum from C. funicola, occasionally can also be observed in C. funicola. However, C. cancroideum is easily distinguishable from C. funicola by its smaller ascomata with the wall of textura angularis (Fig. 3p-t). Because of this, C. cancroideum is retained as a separate species.

Chaetomium indicum Corda Icon. Fung. 4: 38. 1840, Fig. 2e-h.

Description of the epitype: Colonies yellow, aerial hyphae yellow, usually with yellow exudate. Anamorph absent. Ascomata superficial, spherical or ovate, $150-220 \mu \mathrm{m}$ high, 150-200 $\mu \mathrm{m}$ diam., ostiolate. Ascomatal wall composed of brown, irregular, or elongated cells (textura intricata or epidermoidea). Terminal hairs erect, profusely dichotomously branched 4-6 (8) times at wide to acute angles and starting from the lower half part, punctulate or verrucose; Lateral hairs unbranched, seta-like, tapering towards tips. Asci fasciculate, clavate to broadly clavate, stalked, without apical structures, 20-34 × 9-13 $\mu \mathrm{m}, 8$-spored, evanescent. Ascospores are brown, ovate, bilaterally flattened as ellipsoid, 4.5-6 × 3.5-5 × 3-3.5 $\mu \mathrm{m}$, with an apical germ pore at the more attenuated end.

Cardinal temperatures for growth: Minimum about $7{ }^{\circ} \mathrm{C}$, maximum $34{ }^{\circ} \mathrm{C}$, optimum $25^{\circ} \mathrm{C}$.

Specimens examined: Burma, Hinter-indien region, from rotten paper, collection date unknown, A. C. J. Corda, PRM 155406, part of holotype. China, Yunnan Province, Wenshan, from the rhizosphere of Panax Notoginseng, 11 April, 2003, X.-Z. Liu, HMAS 244232 epitype designated here of C. indicum, culture ex-epitype CGMCC 3.14184 (MBT176607). Kenya, Mt. Kenya, from dung of herbivore, R. S. Khan, deposited in CBS collection Apr. 1974, CBS 212.74. Germany, Kiel-Kitzeberg, from air, K. H. Domsch, deposited in CBS collection Dec. 1968, CBS 860.68. China, Yunnan, Wenshan, from the rhizosphere of Panax Notoginseng, 11 April, 2003, X.-Z. Liu, CGMCC 3.14182.

Note: The holotype of $C$. indicum is morphologically similar to that of the epitype, particularly in ascospore morphology. The epitype is geographically close to that of the type locality and phylogenetically consistent with the authentic strains CBS 860.68 and CBS 212.74; both have been examined by von Arx et al (1986). All the examined strains of $C$. indicum produce abundant and dichotomously branched, erect or recurved terminal hairs starting from the lower part (Fig. 1e-g). Chaetomium indicum is significantly lower in MGT $\left(34{ }^{\circ} \mathrm{C}\right)$.

\section{KEY TO THE SPECIES EXAMINED}

1. Length of terminal hairs different enough to show two types of hairs. . . . . . . . . . . . . . . . 2

1. Length of terminal hairs not significantly different. ... 5

2. Ascomatal wall textura angularis .............. 3

2. Ascomatal wall textura intricata ..............4

3. Longer terminal hairs smooth with apices erect ......... . . . . . . . . . . . . . . . . . . C. dolichotrichum

3. Terminal hairs all verrucose with apical branches incurved .................. C. cancroideum

4. Asci clavate. . . . . . . . . . . . . . . . C. funicola

4. Asci obovate. ................ C. subfunicola

5. Terminal hairs arcuate with apical branches strongly reflexed .................... C. reflexum

5. Terminal hairs erect with apical branches not reflexed ...

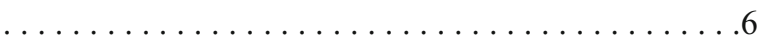

6. MGT $34{ }^{\circ} \mathrm{C}$; terminal hairs typically not rigid. ...... 7

6. MGT $41{ }^{\circ} \mathrm{C}$; terminal hairs conspicuously rigid. ..... 8

7. Ascospores ovate; terminal hairs starting to branch from lower half part ................. indicum

7. Ascospores broadly ovate; terminal hairs starting to branch from upper half part .......... pratense

8. Terminal hairs starting to branch from lower half part.... ...................... ramosissimum

8. Terminal hairs starting to branch from upper half part.... ........................ erectum

\section{Discussion}

The phylogenetic relationships of the eight species in the C. indicum group are well-presented by multigene phylogenies based on the sequences of five unrelated genes. Chaetomium dolichotrichum, represented by its ex-type strain, is morphologically distinct and phylogenetically separated from C. funicola, and therefore von Arx et al.'s synonymization is rejected. The five genes used in this study fail to separate $C$. cancroideum from $C$. funicola. The morphological variation of $C$. cancroideum from $C$. funicola suggests that during the evolution, the divergence of these genes may lag behind that of the morphology. Such incongruence between gene phylogeny and morphology was also recently reported in C. cruentum and C. globosum (Asgari and Zare 
2011). These results indicate that the relationships among species of Chaetomium can be well resolved using the multigene phylogeny, but for a few species it may be necessary to find additional genes with higher resolving ability to recognize their phylogenetic differences.

Our microscopic examination demonstrated the morphological differences among species, including those in their ascomatal hair. Subtle infra-specific morphological variation in ascomatal hairs was also observed, particularly within the species $C$. indicum and C. funicola. These hairs may vary among strains, among generations derived from repeated subculturing, and even among different ascomata in the same culture. This may be interpreted as an adaptive response to the effect of external environments, since ascomatal hairs are the fungal structures directly exposed to the outer environments and serve to protect the ascomata against the environmental stresses (von Arx et al. 1986). By comparison, morphologies of ascospores and asci, as presented here in further detail, are more stable against environmental changes, and thus are more valuable in species delimitation.

Millner (1977) considered that growth responses to temperature had taxonomic value for identifying closely allied species, and designated $C$. indicum, $C$. funicola and $C$. erectum as 'transitional mesophiles' with mycelial growth at $15-37^{\circ} \mathrm{C}$. While von Arx et al. (1986) noted the growth rate of colonies at a specific temperature $\left(28{ }^{\circ} \mathrm{C}\right)$ for each species, a recent study compared the optimum and maximum growth temperatures, as well as the growth rate of 50 strains belonging to 25 Chaetomium species. Their results revealed that all the tested strains within each specific species possessed a consistent MGT, whereas the optimum temperature and the growth rate were shown to vary within species and overlapped between species ( $\mathrm{Li}$ et al. 2012). The present study gave further evidence for the potential usefulness of MGT in delimiting species (Table 1). Growth response of a Chaetomium species to the temperature $37^{\circ} \mathrm{C}$ has also been used as an indicator of its potential for infecting humans (Abbott et al. 1995; Barron et al. 2003). Chaetomium globosum has been known as a causal agent of onychomycosis (Naidu et al. 1991; Stiller et al. 1992). An isolate from a clinic case of fatal brain abscess, which was originally attributed to C. globosum (Anandi et al. 1989), has been re-identified as C. atrobrunneum according to its morphology and ability to grow at $42{ }^{\circ} \mathrm{C}$. The infection of C. globosum was suggested to be confined to cooler areas of the human body due to its restricted growth at $37^{\circ} \mathrm{C}$ (Abbott et al. 1995). Chaetomium funicola has also been reported to cause subcutaneous infection (Koch and Haneke 1965), while the MGT at $37{ }^{\circ} \mathrm{C}$ rules out its potential for deeper infection like C. globosum.

In many cases, Chaetomium species from clinical specimens were left unrecognized because they are usually in sterile form (Abbott et al. 1995). In addition, some Chaetomium strains easily lose sporulating ability in culture
(Tschudy 1937; von Arx et al. 1986). In these cases, DNA sequence data are essential in determining their taxonomic placements and phylogenetic relationships.

Acknowledgments The authors are grateful to Prof. Xing-Zhong Liu for his great contribution to the strain collection and his critical review of the manuscript, to Dr. Lorenzo Lombard for his valuable comments that helped to improve this manuscript, to Prof. Jian-Yun Zhuang for his kind recommendation of the names for the novel species, and to Ms. Xiang-Fei Zhu for her help with the line drawings. The authors also thank the CBS Fungal Collection for providing cultures. Xue-Wei Wang particularly expresses sincere thanks to Prof. Pedro W. Crous for his encouragement and his kind guidance on the epitypification in this study. This work was jointly supported by the National Natural Science Foundation of China (Project No. 30570007) and the Ministry of Science and Technology of P.R. China (No. 2006FY120100).

Open Access This article is distributed under the terms of the Creative Commons Attribution License which permits any use, distribution, and reproduction in any medium, provided the original author(s) and the source are credited.

\section{References}

Abbott SP, Sigler L, McAleer R, McGough DA, Rinaldi MG, Mizell G (1995) Fatal cerebral mycoses caused by the ascomycete Chaetomium strumarium. J Clin Microbiol 33:2692-2698. doi:10. 1128/JCM.41.11

Ames LM (1961) A Monograph of the Chaetomiaceae. US Army Res Dev, Ser 2:125

Anandi V, John TJ, Walter A, Shastry JCM, Lalitha MK, Padhye AA, Ajello L, Chandler FW (1989) Cerebral phaeohyphomycosis caused by Chaetomium globosum in a renal transplant recipient. J Clin Microbiol 27:2226-2229

Asgari B, Zare R (2011) The genus Chaetomium in Iran, a phylogenetic study including six new species. Mycologia 103:863-882. doi:10. 3852/10-349

Barron MA, Sutton DA, Veve R, Guarro J, Rinaldi M, Thompson E, Cagnoni PJ, Moultney K, Madinger NE (2003) Invasive Mycotic Infections Caused by Chaetomium perlucidum, a New Agent of Cerebral Phaeohyphomycosis. J Clin Microbiol 41:5302-5307. doi:10.1128/JCM.41.11

Cannon PF (1986) A revision of Achaetomium, Achaetomiella and Subramaniula, and some similar species of Chaetomium. Trans $\mathrm{Br}$ Mycol Soc 87:45-76

Chivers AH (1915) A monograph of the genera Chaetomium and Ascotricha. Mem Torrey Bot Club 14:155-240

Cooke MC (1873) British fungi. Grevillea 1:174-176

Corda ACJ (1840) Icones Fungorum hucusque Cognitorum 4:1-53

de Cock C, Hennebert GL (1997) A new species of Chaetomium from Ecuador. Mycol Res 101:309-310

Doveri F (2013) An additional update on the genus Chaetomium with descriptions of two coprophilous species, new to Italy. Mycosphere 4:820-846. doi:10.5943/mycosphere/4/4/17

Dreyfuss M (1976) Taxonomische Untersuchungen innerhalb der Gattung Chaetomium. Sydowia 28:50-133

Gené J, Guarro J (1996) A new Chaetomium from Thailand. Mycol Res 100:1005-1009

Glass NL, Donaldson GC (1995) Development of primer sets designed for use with the PCR to amplify conserved genes from filamentous ascomycetes. Appl Environ Microbiol 61:1323-1330 
Greif MD, Stchigel AM, Huhndorf SM (2009) A re-evaluation of genus Chaetomidium based on molecular and morphological characters. Mycologia 101:554-564. doi:10.3852/08-200

Hall TA (1999) BioEdit: a user-friendly biological sequence alignment editor and analysis program for Windows 95/98/NT. Nucleic Acids Symp Ser 41:95-98

Hawksworth DL, Wells H (1973) Ornamentation on the terminal hairs in Chaetomium Kunze ex Fr. and some allied genera. Mycol Pap 134: $1-24$

Kirk PM, Cannon PF, Minter DW, Stalpers JA (2008) Ainsworth \& Bisby's Dictionary of the Fungi, 10th edn. CAB International, Wallingford

Koch HA, Haneke H (1965) Chaetomium funicolum Cooke als moglicher Erreger einer tiefen Mykose. Mykosen 9:23-28

Lee S, Hanlin RT (1999) Phylogenetic relationships of Chaetomium and similar genera based on ribosomal DNA sequences. Mycologia 91: 434-442

Li J, Zhao XM, Wang XW (2012) Growth temperature of Chaetomium species and its taxonomic value. Mycosystema 31:213-222

Mazzucchetti G (1965) Microfungi della cellulosa eddla carta attivita's e inquadramento sistematico-Il genere "Chaetomium". Pubblicazioni Dell' ente nazionale Per La Cellulosa e Per La Carta, Roma

Millner PD (1977) Radial growth responses to temperature by 58 Chaetomium species, and some taxonomic relationships. Mycologia 69:492-502

Millner PD, Motta JJ, Lentz PL (1977) Ascospores, germ pores, ultrastructure, and thermophilism of Chaetomium. Mycologia 69:720-733

Naidu J, Singh SM, Pouranik M (1991) Onychomycosis caused by Chaetomium globosum Kunze. Mycopathologia 113:31-34

O'Donnell K (1993) Fusarium and its near relatives. In: Reynolds R, Taylor JW (eds) The fungal holomorph: mitotic, meiotic and pleomorphic speciation in fungal systematics. CBA International, Wallingford, pp 225-233

O’Donnell K, Cigelnik E (1997) Two divergent intragenomic rDNA ITS2 types within a monophyletic lineage of the fungus Fusarium are nonorthologous. Mol Phylogenet Evol 7:103-116

Posada D (2008) jModelTest: Phylogenetic Model Averaging. Mol Biol Evol 25:1253-1256. doi:10.1093/molbev/msn083

Rambaut A (2009) FigTree v. 1.3.1. Computer program and documentation distributed by the author at http://tree.bio.ed.ac.uk/ software/
Rodríguez K, Stchigel A, Guarro J (2002) Three new species of Chaetomium from soil. Mycologia 94:116-126

Ronquist F, Huelsenbeck JP (2003) MRBAYES 3: Bayesian phylogenetic inference under mixed models. Bioinformatics 19:1572-1574. doi:10.1093/bioinformatics/btg180

Seth HK (1970) A monograph of the genus Chaetomium. Beih Nova Hedwig 37:1-133

Skolko AJ, Groves JW (1948) Notes on seed-borne fungi V.Chaetomium species with dichotomously branched hairs. Can J Res 26:269-280

Skolko AJ, Groves JW (1953) Notes on seed-borne fungi VII. Chaetomium. Can J Bot 31:779-809

Stamatakis A (2006) RAxML-VI-HPC: Maximum Likelihood-based Phylogenetic Analyses with Thousands of Taxa and Mixed Models. Bioinformatics 2:2688-2690. doi:10.1093/bioinformatics/btl446

Stiller MJ, Rosenthal S, Summerbell RC, Pollack J, Chan A (1992) Onychomycosis of the toenails caused by Chaetomium globosum. J Am Acad Dermatol 26:775-776

Swofford DL (2001) PAUP*: phylogenetic analysis using parsimony (and other methods). Version 4.0b8. Sinauer Associates, Sunderland, MA.

Thompson JD, Gibson TJ, Plewniak F, Jeanmougin F, Higgins DG (1997) The ClustalX windows interface: Flexible strategies for multiple sequence alignment aided by quality analysis tools. Nucleic Acids Res 25:4876 4882. doi:10.1093/nar/25.24.4876

Tschudy RH (1937) Experimental morphology of some species of Chaetomium I. Use of cultural reactions in determining species characteristics. Am J Bot 24:472-480

Udagawa S, Toyazaki N, Yaguchi T (1997) A new species of Chaetomium from house dust. Mycoscience 38:399-402

Untereiner WA, Débois V, Naveau FA (2001) Molecular systematics of the ascomycete genus Farrowia (Chaetomiaceae). Can J Bot 79: 321-333. doi:10.1139/cjb-79-3-321

von Arx JA, Dreyfuss M, Müller E (1984) A revaluation of Chaetomium and Chaetomiaceae. Persoonia 12:169-179

von Arx JA, Guarro J, Figueras MJ (1986) The Ascomycete genus Chaetomium. Beih Nova Hedwigia 84:1-162

White TJ, Bruns T, Lee S, Taylor J (1990) Amplification and direct sequencing of fungal ribosomal RNA genes for phylogenetics. In: Innis MA, Gelfand DH, Sninsky JJ, White TJ (eds) PCR protocols: a guide to methods and applications. Academic Press, Inc., New York, pp 315-322 